\title{
PERHITUNGAN HARGA POKOK PRODUK COMPRESSED NATURAL GAS DARI LANDFILL GAS SEBAGAI ENERGI ALTERNATIF PADA TPST BANTAR GEBANG, BEKASI
}

\author{
Srilarakasuri P Ardiagarini, Anthony Riman, Helena J Kristina \\ Jurusan Teknik Industri, Universitas Pelita Harapan-Tangerang \\ Jl. M.H.Thamrin Boulevard, Tangerang, 15811 Banten \\ ardiagarini@gmail.com, anthony.riman@uph.edu, helena.kristina@uph.edu
}

\begin{abstract}
Abstrak
Pergeseran konsumsi bahan bakar minyak ke bahan bakar berbasis gas, sebagai alternatif energi untuk sektor transportasi di Indonesia diperlukan. Salah satu renewable energy yang saat ini populer adalah biogas. Landfill gas (LFG) yaitu biogas yang dihasilkan dari timbunan sampah domestik dalam jumlah yang besar pada suatu lahan. Penelitian ini dibuat dengan tujuan menghitung harga pokok untuk memproduksi CNG yang terbuat dari LFG yang dihasilkan oleh TPST Bantar Gebang. CNG dapat digunakan untuk menggerakkan mesin-mesin industri dan juga kendaraan mobil. TPST Bantar Gebang termasuk sebagai salah satu institusi yang dapat mengelola sampah dengan baik memiliki 95 area aktif Ha yang dapat menghasilkan gas TPA (LFG) dengan kapasitas 5.971 Nm3/hour. Kandungan utama dari gas yang terbentuk adalah metana $\left(\mathrm{CH}_{4}\right)$ dan karbondioksida $\left(\mathrm{CO}_{2}\right)$ diikuti dengan gas-gas lainnya dengan komposisi yang relatif kecil. LFG dapat dikonversi ke CNG menggunakan Acrion CO2 WASH yang melepaskan CH4 dari gas lainnya. Hasil penelitian menggunakan 2 skenario jangka waktu, yaitu selama 5 tahun dan 10 tahun, didapatkan kapasitas LFG yang digunakan saat ini untuk memproduksi CNG hanya $5 \%$ dari kapasitas LFG, yaitu sebesar 7,500 Nm $3 /$ hari, dan menghasilkan CNG sebanyak 3,570 $\mathrm{Nm}^{3} / \mathrm{hari}^{2}$. Harga pokok produksi produk CNG yang dihasilkan dalam penelitian ini adalah Rp 160,00/ liter dengan perhitungan jangka waktu selama 5 tahun dan Rp 150,00 /liter dengan perhitungan jangka waktu selama 10 tahun.
\end{abstract}

Kata kunci: renewable energy, biogas, TPST bantar gebang, LFG, CNG, harga pokok produksi

\begin{abstract}
In light of shifting fuel consumption from oil-based to gas-based fuel, researches on renewable energy as an alternative energy for trasportation sector in Indonesia are needed. Meanwhile, TPST Bantar Gebang has $95 \mathrm{Ha}$ active area which can produce landfill gas (LFG) with the capacity of 5,971 $\mathrm{Nm}^{3} / \mathrm{hour}$. Landfill gas is biogas produced as a result of anaerob decomposition on organic material from piled sanitary landfill waste; $\mathrm{CNG}$ is compressed natural gas of $\mathrm{CH}_{4}$. $\mathrm{CNG}$ can be used as an altenative fuel for transport vehicles. LFG can be converted to $\mathrm{CNG}$ using Acrion $\mathrm{CO}_{2}$ WASH l machine which detaches $\mathrm{CH}_{4}$ from other gas. The LFG used to calculate cost of goods sold of this product is only five percent of the total LFG capacity that can presently be produced at TPST Bantar Gebang. The input is LFG of $7,500 \mathrm{Nm}^{3} /$ day and the output is $C \mathrm{NG}$ of 3,570 $\mathrm{Nm}^{3} /$ day. Two time-point scenarios are used in the cost of goods sold calculation: five years and 10 years. Total expenditure at those time-points is divided by CNG capacity produced each year. The product's costs of goods sold in five years time is Rp 160/litre and in ten years time is $R p$ 150/liter.
\end{abstract}

Key words: renewable energy, biogas, TPST bantar gebang, LFG, CNG ,cost of goods sold

\section{PENDAHULUAN}

Saat ini, hampir seluruh sektor penunjang kehidupan manusia sangat bergantung akan energi. Energi yang digunakan pada umumnya adalah energi minyak bumi, gas alam, dan batubara, serta nuklir. Energi tersebut dikategorikan dalam non-renewable energy atau energi yang tidak dapat diperbaharui, karena siklus memproduksi energi tersebut terjadi dalam kurun waktu yang sangat lama. Meski jumlah energi tersebut relatif masih banyak, namun para ilmuwan saat ini telah dapat menghitung perkiraan jumlah yang tersedia, sehingga jumlah persediaan energi yang ada saat ini dibanding dengan proyeksi tingkat kebutuhan manusia terhadap energi, diprediksikan bahwa sampai waktu tertentu 
non-renewable energy tersebut akan habis. Oleh karena itu, untuk menjamin pasokan energi agar tetap tersedia, manusia telah mengembangkan teknologi untuk mengolah sumber daya alam sekitar untuk dimanfaatkan sebagai energi alternatif yang bersifat renewable untuk menunjang kebutuhan manusia terhadap energi.

Salah satu renewable energy yang saat ini populer adalah biogas. Biogas terbentuk akibat proses fermentasi oleh bakteri yang bereaksi pada bahan-bahan organik dalam keadaan anaerob (tanpa udara). Bahanbahan organik yang dapat berfermentasi adalah limbah peternakan, limbah pertanian, limbah industri, dan sampah organik. Biogas tersebut sifatnya mudah terbakar dan dapat terbentuk dalam waktu yang relatif pendek. Biogas dapat dihasilkan dengan bantuan sejumlah tangkitangki serta peralatan mesin (anaerobic digester) dan landfill (lahan/area). Gas yang timbul dari landfill disebut sebagai landfill gas. Landfill gas (LFG) yaitu biogas yang dihasilkan dari timbunan sampah domestik dalam jumlah yang besar pada suatu lahan.

Kandungan utama dari gas yang terbentuk adalah metana $\left(\mathrm{CH}_{4}\right)$ dan karbondioksida $\left(\mathrm{CO}_{2}\right)$ diikuti dengan gasgas lainnya dengan komposisi yang relatif kecil. Metana dan karbondioksida dapat mengakibatkan green house effect dengan menipiskan ozon. Oleh sebab itu, jika dilepas begitu saja, gas-gas ini menimbulkan dampak lingkungan yang serius, namun jika dikumpulkan dan dikelola dengan baik, gas tersebut dapat dimanfaatkan menjadi energi yang berguna bagi kehidupan.

TPST Bantar Gebang termasuk sebagai salah satu institusi yang dapat mengelola sampah dengan baik. Dengan bekerjasama dengan PT. N dan G, TPST Bantar Gebang tidak hanya mampu memproduksi kompos, tetapi juga mampu mengumpulkan LFG untuk diproses menjadi listrik hingga 10.5 MW. Saat ini, (Mei 2012) PT. N telah menjual listrik dengan harga Rp 820/kW kepada Perusahaan Listrik Negara.

Saat ini, pemerintah sedang mendorong masyarakat untuk melakukan konversi atau pengalihan penggunaan BBM menjadi BBG atau bahan bakar gas. Hal ini dilakukan untuk mengurangi penggunaan BBM bersubsidi, agar pengeluaran dana APBN dapat berkurang alias hemat. Selain itu, BBG lebih bersifat ramah lingkungan dibandingkan dengan BBM, maka upaya konversi $\mathrm{BBG}$ saat ini marak dilakukan untuk dapat memenuhi kebutuhan masyarakat dalam mengkonsumsi energi. Selain itu, BBG juga dapat dibuat dari sumber yang dapat diperbarui, salah satu contohnya adalah sampah.

Berdasarkan latar belakang yang telah dijelaskan, pokok permasalahan yang muncul adalah masih kurangnya pengkajian mengenai bahan bakar gas CNG yang bersifat terbarukan, yaitu dari sampah untuk diterapkan di Indonesia. Dengan demikian, perlu dilakukan suatu studi mengenai renewable energy dari sampah, agar dapat mengatasi permasalahan pengalihan BBM menjadi BBG, sekaligus dengan cara pemanfaatan gas yang timbul pada sampah (LFG).

Sebagai langkah awal dalam program konversi BBM ke BBG, penelitian ini dibuat dengan tujuan untuk menghitung harga pokok untuk memproduksi CNG yang terbuat dari LFG yang dihasilkan oleh TPST Bantar Gebang

\section{METODE PENELITIAN}

Data yang dikumpulkan dalam penelitian ini adalah data mengenai sistem yang saat ini beroperasi secara nyata di TPST Bantar Gebang dalam mengekstraksi gas, serta data-data terkait dalam merancang suatu sistem usulan dalam memproduksi CNG di Indonesia. Data-data yang terkait pada sistem saat ini adalah data operasional sampah, data produksi gas, jumlah tenaga kerja yang ada, serta aktivitas-aktivitas yang dilakukan dalam mengekstraksi gas beserta biaya-biaya yang timbul pada aktivitas tersebut. Data tersebut didapat dari sumber-sumber seperti TPST Bantar Gebang, BPPT (Badan Penerapan dan Pengkajian Teknologi), buku, jurnal, serta e-jurnal dan artikel yang tersedia secara luas di internet.

Sedangkan pada pengumpulan data mengenai sistem yang diusulkan, data yang dikumpulkan adalah data tentang informasi 
alat dan mesin, serta biaya-biaya untuk melengkapi keperluan lainnya dalam mewujudkan sistem tersebut. Data-data tersebut banyak didapat melalui buku, jurnal, serta e-jurnal dan artikel yang tersedia secara luas di internet.

Pada sistem yang sudah ada, pengolahan data dilakukan dengan merinci aktivitas yang terkait secara langsung dengan kegiatan ekstraksi atau produksi gas. Data biaya pada produksi yang terkait dirinci per aktivitas dan diolah menggunakan konsep activity based costing, namun hanya terbatas pada aktivitas bagian produksinya saja, dikarenakan adanya keterbatasan dalam pengambilan data selain bagin produksi. Seluruh biaya dijumlahkan dan dibagi dengan jumlah kapasitas sistem saat ini untuk mendapatkan harga pokok, dengan 2 skenario jangka waktu yaitu selama 5 tahun dan 10 tahun.

Kemudian pada sistem usulan, dari studi pustaka yang telah dilakukan, dilakukan perincian biaya-biaya yang diperlukan dalam merancang suatu sistem baru. Aset-aset dalam rancangan anggaran tersebut dijumlah untuk mendapatkan jumlah investasi yang diperlukan. Biaya investasi diasumsikan didapat dari pinjaman bank dengan asumsi suku bunga sebesar $8 \%$ dan inflasi sebesar $2 \%$. Biayabiaya tersebut kemudian dibagi dengan jumlah kapasitas produksi untuk menghitung harga pokoknya. Perhitungan ini juga menggunakan 2 skenario jangka waktu, yaitu selama 5 tahun dan 10 tahun.

Setelah harga pokok masing-masing telah didapat, harga pada kedua sistem tersebut kemudian dijumlah dan dibagi dengan jumlah kapasitas output yang tersedia. Satuan untuk harga pokok yang didapat pada akhirnya adalah rupiah per liter. Angka inilah yang diusulkan kepada pihak PT.N dan TPST Bantar Gebang untuk dijadikan pertimbangan bisnis dalam menentukan harga jual CNG untuk dikomersilkan kepada masyarakat.

Adapun pembatasan masalah yang digunakan dalam penelitian ini adalah:

- Jangka waktu pengambilan data dimulai dari Januari hingga Juni 2012 di TPST Bantar Gebang, Bekasi
- Penulisan notasi angka menggunakan notasi standar Amerika, yaitu (.) sebagai koma dan (,) sebagai titik. (contoh: 2,012.5 dibaca sebagai dua ribu dua belas koma lima)

- Tidak membahas proses rinci pada mesin Acrion $\mathrm{CO}_{2}$ WASH

- Perhitungan harga pokok produk (HPP) dibagi menjadi dua bagian, yaitu harga pokok pada produk yang dihasilkan dari sistem saat ini (LFG) dan harga pokok dari produk sistem yang diusulkan (CNG). Pada akhirnya HPP keduanya dijumlahkan untuk mendapatkan harga pokok produk dari sistem yang telah digabungkan

- Perhitungan HPP dalam 2 skenario, yaitu dengan jangka panjang waktu 5 tahun dan 10 tahun

- Tidak memasukkan perhitungan pajak dalam menghitung HPP

- Tidak memasukkan perhitungan aktivitas selain produksi dalam menghitung harga pokok pada sistem saat ini

- Konversi mata uang yang digunakan adalah kurs jual tanggal 4 Mei 2012 (US \$1 = Rp 9,510)

- Suku bunga yang digunakan dalam perhitungan adalah $8 \%$, dengan inflasi sebesar 6\%

\section{SISTEM SAAT INI DI TPST (TEMPAT PEMROSESAN SAMPAH TERPADU) BANTAR GEBANG}

Pemberian nama sentra industrialisasi sampah ini, disebabkan oleh karena area tersebut sedang dalam pengembangan dalam memproses dan menjadikan sampah menjadi suatu produk yang bermanfaat, serta dapat menerapkan suatu pemrosesan sampah secara optimal, sehingga dapat mengurangi dampak kepada lingkungan. Total nilai investasi yang ditanamkan untuk industrialisasi TPST Bantar Gebang ini senilai Rp 700 miliar. Seluruh luas TPST adalah $110 \mathrm{Ha}$, dibagi menjadi lahan fasilitas dan lahan efektif. Lahan efektif memiliki luas $95 \mathrm{Ha}$, yang dibagi menjadi 5 zona yaitu, zona I, II, III, IV, dan V (Gambar 1). 
Fasilitas pemrosesan sampah yang dilakukan pada TPST Bantar Gebang antara lain: Sanitary Landfill, Unit Composting, Instalasi Pengolahan Air Sampah, dan Power Plant. Sanitary landfill adalah suatu metode pada TPA, yang sebelum sampah ditimbun pada suatu lahan, dilakukan pembuatan lapisan-lapisan agar air lindi (air pada sampah) tidak menyebar ke dalam tanah. Sampah yang ditimbun kemudian dikonstruksi sesuai dengan lahan yang ada dan dipadatkan menggunakan alat berat secara berkala. Unit composting adalah suatu unit yang mengolah sampah pasar (dari pasar-pasar tradisional sekitar saja) untuk diolah menjadi kompos.

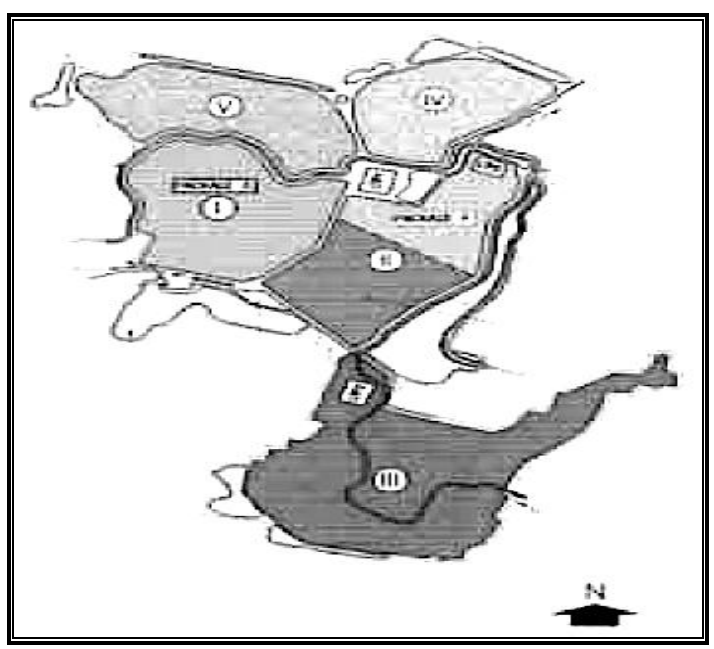

Gambar 1 Peta area TPST Bantar Gebang (Kajima, 2005)

Jumlah sampah yang diolah sebanyak 500 ton per hari. Dengan memakan waktu 1 - 2 bulan, pengomposan dilakukan hingga berbentuk bubuk, dan dijual ke pasar luar pulau seperti Pulau Sumatera. Selain itu, ada juga unit pengolahan yang bernama IPAS. IPAS (Instalasi Pengolahan Air Sampah) adalah suatu area untuk menampung air sampah/air lindi yang terjadi pada landfill. Air lindi yang ditampung kemudian diproses agar tidak mengandung zat-zat yang berbahaya, sehingga dapat mengurangi pencemaran pada lingkungan. Yang terakhir adalah unit power plant.

Unit ini merupakan salah satu bentuk cerminan partisipasi terhadap program LFGTE (Land Fill Gas to Energy). Unit ini melakukan penangkapan LFG yang timbul pada landfill, untuk diolah menjadi tenaga listrik. Power plant dioperasikan pada Power House yang terletak pada pusat TPST Bantar Gebang.

Sampah yang masuk setiap harinya adalah rata-rata sebanyak 6,000 ton. Seluruh area TPST Bantar Gebang adalah seluas 110 ha, dengan area operasi efektif untuk diambil gasnya adalah seluas $95 \mathrm{Ha}$ $\left(9,500,000 \mathrm{~m}^{2}\right)$. Menurut wawancara yang telah dilakukan dengan pihak pengelola, jika dilakukan pemadatan sampah menggunakan alat berat, 1 ton sampah setara dengan volume $4 \mathrm{~m}^{3}$, sehingga densitas sampah dapat diketahui yaitu 0.25 ton $/ \mathrm{m}^{3}$. Tinggi tumpukan sampah adalah rata-rata $25 \mathrm{~m}$, maka volume sampah pada TPST hingga saat ini adalah:

$$
950,000 \mathrm{~m}^{2} \times 25 \mathrm{~m}=23,750,000 \mathrm{~m}^{3}
$$

dan tonase keseluruhan sampah adalah,

$$
\begin{aligned}
& \frac{0.25 \text { ton }}{m^{3}}=\frac{x \text { ton }}{23,750,000 \mathrm{~m}^{3}} \\
& x \mathrm{~m}^{3} \text { ton }=(0.25 \times 23,750,000) \mathrm{m}^{3} \text { ton } \\
& x=5,937,500 \text { ton }
\end{aligned}
$$

Jumlah sampah ini pada kenyataannya masih terus bertambah setiap harinya. Namun karena adanya keterbatasan dalam pengambilan data, maka diasumsikan jumlah sampah pada seluruh area aktif adalah 5,937,500 $\mathrm{m}^{3}$ ton. Dalam mengubah sampah menjadi listrik, metode yang dipakai adalah pengolahan yang menggunakan gas engine. Selain gas engine, teknologi dalam membuat listrik dari sampah yang paling populer di dunia adalah dengan menggunakan metode incineration atau pembakaran, metode ini adalah metode alternatif ketika gas engine mengalami masalah. Dalam menghasilkan produk listrik, harus melalui dua tahapan sistem, yaitu ekstraksi dan utilisasi.

Pada sistem ekstraksi, LFG akan melewati rangkaian extraction gas well yang terdiri dari gas well dan pipa-pipa penyambung untuk dikumpulkan kepada power house. Pada power house, terdapat suatu rangkaian extraction plant atau mesin ekstraksi untuk menarik LFG dari tiap-tiap gas well. Mesin ekstraksi ini sekaligus berperan dalam melakukan pre-cleaning, yaitu pembersihan gas dengan melalui 
pengeringan serta menurunkan suhu LFG yang semula hingga mencapai $70{ }^{\circ} \mathrm{C}$, menjadi $15{ }^{\circ} \mathrm{C}$. Mesin ekstraksi atau precleaning station ini terdiri dari water knockout, mesin chiller, serta blower. Setelah itu, LFG baru dapat ditransfer kepada sistem utilisasi. Dengan sejumlah mesin dan fasilitas yang ada, kapasitas listrik yang dapat dihasilkan saat ini adalah sejumlah 10.5 MW. 5\% dari keseluruhan jumlah listrik yang dihasilkan tersebut digunakan kembali untuk operasional TPST Bantar Gebang, sedangkan 95\% sisanya dijual kepada Perusahaan Listrik Negara (PLN). Diagram aliran proses (gambar 2) menjelaskan tentang alur yang terdapat pada bagian proses saja untuk menghasilkan produk yaitu listrik, sehingga ruang lingkup yang ditunjukkan menjadi lebih sempit.

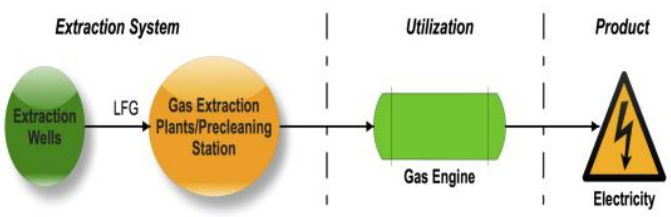

Gambar 2 Aliran Proses Pada PLTSa

\section{USULAN KONSEP ALIRAN PROSES PADA CNG}

Gambar 3, menunjukkan diagram aliran proses dalam memproduksi CNG. Produksi CNG menggunakan extraction system yang sudah berjalan pada TPST Bantar Gebang saat ini Dengan demikian, modifikasi yang dilakukan adalah pada tahap utilisasi serta produk yang dihasilkan. Sistem yang digunakan dalam tahap utilisasi adalah Acrion $\mathrm{CO}_{2}$ WASH. Acrion Technologies Inc. adalah suatu perusahaan yang bergerak di bidang konsultasi mengenai proses kimia, berbasis di Cleveland, Ohio. Perusahaan ini ahli dalam mendesain proses pengolahan LFG dan bekerjasama dengan U.S. Department of Energy. Sistem yang digunakan dalam pemisahan LFG ini menggunakan $\mathrm{CO}_{2}$ liquid untuk dialirkan dari atas dan LFG dialirkan dari dasar, sehingga terjadi proses counter-current dan terjadi penyaringan karbondioksida dan kandungan gas lainnya, sehingga kadar karbondioksida dalam LFG akan berkurang.

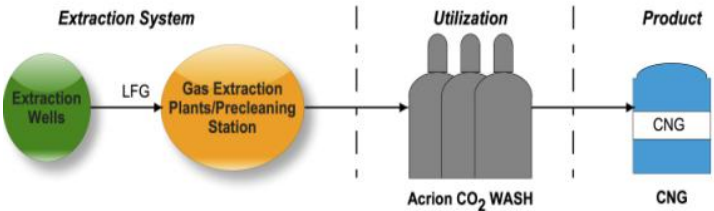

Gambar 3 Aliran proses pada CNG

$\mathrm{CO}_{2}$ liquid merupakan karbondioksida murni $(99.99 \%)$ dan dapat diolah lagi hingga menjadi food grade liquid, dan dapat dijual sebagai bahan dasar minuman dan lainnya. Output dari mesin ini ada dua, karbondioksida cair dan LFG. yang sudah dibersihkan. LFG yang telah dibersihkan secara kasar pada tahapan awal memiliki kandungan metana hingga mencapai $75 \%$ dan karbondioksida 25\%, dan sudah terlepas dari kontaminan lainnya seperti $\mathrm{H}_{2} \mathrm{~S}$, siloxan, dan lainnya. (Edwards\&Kelcey,2005).

Untuk dapat menghasilkan CNG, upaya pemurnian masih dilanjutkan dengan melakukan proses lebih lanjut pada rangkaian mesin tersebut dengan menggunakan kompresor bertekanan tinggi serta vessel yang digunakan untuk storage. Rincian proses pada sistem tidak dijelaskan karena literatur rincian proses tidak disebarkan secara komersil. Biaya yang dikeluarkan untuk mesin ini adalah sebesar $\$ 12,000,000$ USD (Sprague et al, 2009).

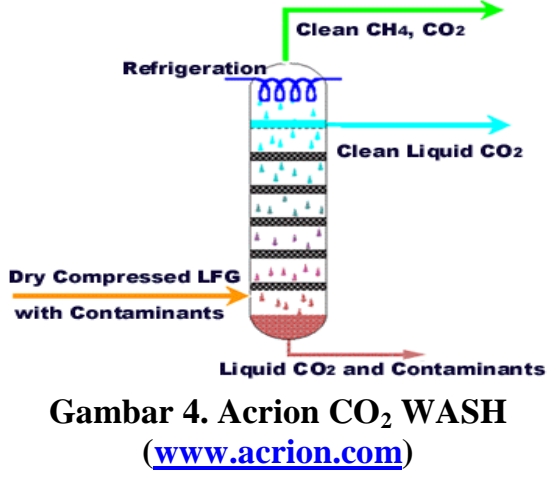

Kapasitas operasi mesin tersebut dapat mengolah LFG sebanyak 140,000 cu ft $\left(3,964 \mathrm{Nm}^{3}\right)$ per hari dan menghasilkan 1 ton $\mathrm{CO}_{2}$ liquid komersil dan 70,000,000 btu fuel cell grade methane yaitu setara dengan 1,982.4 $\mathrm{Nm}^{3} \quad$ (www.netl.doe.gov). Berdasarkan informasi tersebut, dapat dilihat bahwa dengan input yang terbatas, 
outputnya tersaring sebanyak 50\% dari keseluruhan input yang ada, sehingga jika mesin tersebut digunakan, outputnya dapat diasumsikan yaitu 50\% dari total input.

\section{PERBANDINGAN HARGA POKOK PRODUK LFG PADA SISTEM SAAT INI DAN SISTEM USULAN}

Harga pokok produk ditentukan pada sebagian sistem saja menggunakan activity based costing. Aktivitas yang ditelusuri adalah pada aktivitas production pada extraction system-nya saja. Dalam menghitung harga pokok, data tenaga kerja yang diperhitungkan adalah data tenaga kerja langsung sebanyak 90 orang pada bagian production pada extraction system. Menurut wawancara, gaji rata-rata $\mathrm{Rp}$ $3,000,000$ per bulan. Diasumsikan untuk biaya lembur dan tunjangan diperhitungkan pada pembiayaan lain, sehingga tidak dihitung. Pengeluaran untuk gaji per bulan adalah sebesar:

\section{0 orang / bulan $\times R p 3,000,000$ / orang}

\section{$=R p 270,000,000 /$ bulan}

Dikarenakan gas engine berproduksi selama 24 jam/hari, extraction system juga berproduksi selama 24 jam/hari juga. Diasumsikan untuk gas engine tersebut tidak ada masalah, sehingga tidak perlu dilakukan shut down dan juga pada extraction system-nya pun menjadi harus siap beroperasi selama 24 jam (720 jam per bulan). Dalam menghitung harga pokok lebih terfokus, yaitu pada aktivitas production pada extraction system. Aktivitas-aktivitasnya adalah antara lain yaitu: Monitor alat dan mesin pada landfill, Monitor mesin ekstraksi pada power house, Maintenance alat dan mesin pada landfill dan power house.

Komponen biaya yang muncul pada aktivitas monitor alat dan mesin pada landfill adalah biaya tenaga kerja dan biaya listrik. Biaya listrik adalah pada pengoperasian compressor, biaya bahan bakar digunakan pada alat transportasi ke tiap-tiap gas well untuk pengecekan yang harus dilakukan secara berkala. Tenaga kerja pada aktivitas ini adalah 76 orang.

Biaya listrik yang timbul adalah listrik untuk mengoperasikan compressor. Untuk mengoperasikan 20 unit compressor dibutuhkan energi sebanyak 79,200 $\mathrm{kWh} /$ bulan. Dengan demikian, biaya listrik per $\mathrm{kWh}$ diasumsikan sama dengan harga penjualan listrik kepada PT.PLN yaitu sebesar Rp 820/kWh, sehingga pengeluaran biaya listrik menjadi:

$$
\text { 79,200kWh/ bulan } \times R p 820 / k W h
$$

$=R p$ 64,944,000/bulan

Selain listrik, biaya yang perlu dikeluarkan pada aktivitas ini adalah biaya bahan bakar untuk transportasi. Dalam memonitor landfill, digunakan sepeda motor sebagai alat transportasi.

Biaya operasional sepeda motor tersebut adalah bahan bakar, dimana jatah bahan bakar per bulan dalam memonitor landfill adalah diperkirakan sebesar 60 liter per bulan. Rata-rata penggunaan konsumsi bahan bakar pada sepeda motor adalah 58.1 $\mathrm{km} /$ liter, sehingga jarak yang dapat ditempuh dengan mengisi bahan bakar 60 liter adalah $3,486 \mathrm{~km}$. Bahan bakar yang umum digunakan sepeda motor adalah bensin premium dengan harga $\mathrm{Rp} 4,500$, sehingga pengeluaran bahan bakar menjadi:

60liter / bulan $\times R p$ 4,500 / liter

\section{$=R p 270,000 /$ bulan}

Berikutnya adalah aktivitas monitor mesin ekstraksi pada power house. Komponen biaya yang muncul pada aktivitas tersebut adalah biaya tenaga kerja dengan biaya listrik untuk mengoperasikan mesin blower dan chiller. Konsumsi energi listrik untuk kedua mesin ini dapat dilihat pada tabel 4.4. Total energi yang dikonsumsi per bulan adalah 129,600 kWh per bulan, sehingga didapat perhitungan pengeluaran sebanyak :

129,600kWh/ bulan $\times R p 820 / k W h$

$$
=R p 106,272,000 / \text { bulan }
$$

Dan yang terakhir adalah aktivitas maintenance alat dan mesin pada landfill. Biaya maintenance adalah sebesar $7 \%$ per tahun dari biaya beli mesin dan biaya persiapan (preparation) lainnya, sehingga perlu dilakukan perincian biaya-biaya alat dan mesin yang digunakan dalam extraction system. Total biaya preparation adalah $\mathrm{Rp}$ 144,799,600,000. Dengan demikian, 
pengeluaran biaya maintenance per tahunnya sebesar:

Rp 144,799,600,000 × 7\% / tahun

$=R p 10,135,972,000 /$ tahun

Sehingga pengeluaran per bulannya didapat,

Rp 10,135,972,000/tahun

12 bulan / tahun

$=R p 844,644,333 /$ bulan

Selain mesin dan alat yang perlu dipasang, dalam memonitor landfill dibutuhkan methane monitor. Alat tersebut dioperasikan oleh pekerja dalam memonitor komposisi metana pada LFG pada tiap titik gas well. TPST Bantar Gebang memiliki methane monitor sebanyak 2 macam, yaitu mobile dengan harga Rp 120,000,000 sebanyak 2 unit dan permanent sebanyak 1 unit dengan harga Rp 250,000,000. Telah dihitung pengeluaran per bulan untuk aktivitas production pada extraction system yaitu sebanyak Rp 1,286,150,333 per bulan sehingga biaya operasi per tahunnya menjadi:

$R p 1,286,150,333$ / bulan $\times 12$ bulan / tahun

$=R p 15,433,804,000 /$ tahun

Dari biaya tersebut diasumsikan setiap tahunnya terjadi inflasi sebesar $6 \%$. Tabel 1, menunjukkan jumlah biaya pengeluaran dalam 2 skenario.

Tabel 1 Tabel Jumlah Pengeluaran Setelah Inflasi

\begin{tabular}{ccc}
\hline Thn & $\begin{array}{c}\text { BP + inflasi 6\% } \\
(\mathrm{Rp})\end{array}$ & Total (Rp) \\
\hline 2013 & $15,433,804,000$ & \\
2014 & $16,359,832,240$ & \\
2015 & $17,341,422,174$ & \\
2016 & $18,381,907,505$ & Total 5 tahun: \\
2017 & $19,484,821,955$ & $87,001,787,874$ \\
2018 & $20,653,911,272$ & \\
2019 & $21,893,145,949$ & \\
2020 & $23,206,734,706$ & \\
2021 & $24,599,138,788$ & Total 10 tahun: \\
2022 & $26,075,087,115$ & $203,429,805,705$ \\
\hline
\end{tabular}

Telah diketahui jumlah output LFG dari extraction system adalah sejumlah $5,971 \mathrm{Nm}^{3} /$ jam. Jika diasumsikan mesin extraction system terus bekerja selama 24 $\mathrm{jam} /$ hari selama 10 tahun secara non-stop, maka jumlah output yang dapat dihasilkan adalah seperti pada tabel 4.9 berikut dengan jangka waktu jam, hari, bulan dan tahun.

Penelusuran kapasitas per jangka waktu tersebut dilakukan untuk dapat mengetahui kapasitas LFG pada setiap skenario jangka waktu yang telah ditentukan yaitu 5 tahun dan 10 tahun, dapat dilihat pada tabel 2 .

Tabel 2 Kapasitas Output LFG Extraction System

\begin{tabular}{lrl}
\hline Jangka Waktu & \multicolumn{2}{c}{ Kapasitas LFG } \\
\hline $\begin{array}{l}\text { 1 Jam } \\
\text { 1 Hari } \\
\text { (24 jam) }\end{array}$ & 5,791 & $\mathrm{Nm}^{3} /$ jam \\
$\begin{array}{l}\text { 1 Bulan } \\
\text { (30hari) }\end{array}$ & 433,752 & $\mathrm{Nm}^{3} /$ hari \\
1 Tahun \\
$\begin{array}{l}\text { (12 bulan) } \\
\text { 5 Tahun }\end{array}$ & $50,034,240$ & $\mathrm{Nm}^{3} /$ tahun \\
10 Tahun & $250,171,200$ & $\begin{array}{l}\mathrm{Nm}^{3} / 5 \\
\text { tahun } \\
\mathrm{Nm} / 10 \\
\text { tahun }\end{array}$ \\
\hline
\end{tabular}

Dengan seluruh informasi yang telah dijelaskan, maka didapat dihitung harga pokok produk LFG. HPP LFG dihitung dengan membagi jumlah pengeluaran dengan kapasitas LFG yang dapat dihasilkan dalam kurun waktu sesuai dengan skenario yang ada. Satuan dari HPP yang dihitung adalah dalam rupiah per norm meter kubik.

Skenario 1: jangka waktu 5 tahun $\frac{R p 87,001,787,874}{250,171,200 \mathrm{Nm}^{3}}=R p \quad 348 / \mathrm{Nm}^{3}$

Skenario 2 : jangka waktu 10 tahun $\frac{R p 203,429,805,705}{500,342,400 \mathrm{Nm}^{3}}=R p \quad 407 / \mathrm{Nm}^{3}$

Sedangkan, pada sistem usulan hanya dibutuhkan 5\% saja dari jumlah tersebut sehingga jumlah yang digunakan menjadi $7,500 \mathrm{Nm}^{3} /$ hari. Tabel 3, menampilkan Jumlah kapasitas dari LFG pada setiap jangka waktunya yaitu jam, hari, bulan, dan tahun. Penelusuran kapasitas per jangka waktu tersebut dilakukan untuk dapat mengetahui kapasitas LFG pada setiap skenario yaitu 5 tahun dan 10 tahun. 
Tabel 3 Kapasitas Output LFG Sistem Usulan

\begin{tabular}{lrl}
\hline Jangka Waktu & \multicolumn{2}{c}{ Kapasitas LFG } \\
\hline $\begin{array}{l}\text { 1 Hari (24 jam) } \\
\text { 1 Bulan }\end{array}$ & 7,500 & $\mathrm{~m}^{3} /$ hari \\
(30hari) & 225,000 & $\mathrm{~m}^{3} / \mathrm{bulan}$ \\
1 Tahun (12 & $2,700,000$ & $\mathrm{~m}^{3} /$ tahun \\
bulan) & & \\
5 Tahun & $13,500,000$ & $\mathrm{~m}^{3} / 5$ tahun \\
10 Tahun & $27,000,000$ & $\mathrm{~m}^{3} / 10$ tahun
\end{tabular}

Hasil perhitungan HPP adalah dalam satuan rupiah per norm meter kubik.

Skenario 1:

$\frac{R p 87,001,787,874}{13,500,000 \mathrm{Nm}^{3}}=R p \quad 6,446 / \mathrm{Nm}^{3}$

Skenario 2 :

$\frac{R p 203,429,805,705}{27,000,000 \mathrm{Nm}^{3}}=R p \quad 7,534 / \mathrm{Nm}^{3}$

Perhitungan HPP untuk masingmasing produk LFG dan CNG telah dilakukan. Pada dasarnya, LFG adalah bahan dasar pembuat CNG. Sistem yang sudah ada saat ini dijumlahkan dengan sistem yang diusulkan, sehingga dihasilkan produk yang diinginkan yaitu CNG. Dengan demikian, penentuan HPP CNG keseluruhan dilakukan dengan menjumlahkan HPP LFG dari sistem yang ada saat ini, dengan HPP CNG pada sistem usulan.

Dalam menjumlahkan harga pokok kedua produk tersebut, pertama-tama dilakukan dengan mengkonversi HPP masing-masing dalam satuan per jam. Telah dijelaskan bahwa dari kapasitas per jam LFG yaitu 7,500 $\mathrm{Nm}^{3}$, akan didapat 3,250 $\mathrm{Nm}^{3}$ produk CNG, sehingga HPP per meter kubik yang didapat dikalikan dengan jumlah masing-masing. Kemudian keduanya dijumlah dan didapat HPP total per jam. Total HPP tersebut kemudian dibagi dengan kapasitas output yang ada, yaitu sejumlah kapasitas CNG sebanyak 3,250 $\mathrm{Nm}^{3}$, sehingga didapat angka HPP untuk setiap norm meter kubik.
Tabel 4 HPP per norm meter kubik dan kapasitas

\begin{tabular}{|c|c|c|}
\hline Skenario & $\begin{array}{c}\mathrm{LFG} \\
\left(\mathrm{Rp} / \mathrm{m}^{3}\right)\end{array}$ & $\begin{array}{c}\mathrm{CNG} \\
\left(\mathrm{Rp} / \mathrm{m}^{3}\right)\end{array}$ \\
\hline $\begin{array}{l}\text { Skenario } 1 \\
\text { (5 tahun) }\end{array}$ & 6,446 & 146,773 \\
\hline \multirow{2}{*}{$\begin{array}{l}\text { Skenario } 2 \\
\text { (10 tahun) }\end{array}$} & 7,534 & 134,144 \\
\hline & $\begin{array}{c}\mathrm{LFG} \\
\left(\mathrm{m}^{3} / \text { hari }\right)\end{array}$ & $\begin{array}{c}\text { CNG } \\
\left(\mathrm{m}^{3} / \text { hari }\right)\end{array}$ \\
\hline Kapasitas & 7,500 & 3,750 \\
\hline
\end{tabular}

Pada tabel 4, didapatkan rekapitulasi harga pokok setiap produk yang telah dihitung untuk setiap skenario. Setelah harga pokok produk dari LFG dan CNG didapat, maka jumlah per norm meter kubik tersebut dikalikan dengan kapasitas per hari masing-masing produk. Mengacu pada tabel 4, maka HPP per hari untuk setiap produk didapat sebagai berikut.

Skenario 1:

$$
\begin{aligned}
L F G & =R p \quad 6,446 / \mathrm{Nm}^{3} \times 7,500 \mathrm{Nm}^{3} / \text { hari } \\
& =R p \quad 48,345,000 / \text { hari } \\
C N G & =R p \quad 146,773 / \mathrm{Nm}^{3} \times 3,750 \mathrm{Nm}^{3} / \text { hari } \\
& =R p \quad 550,398,750 / \text { hari }
\end{aligned}
$$

Skenario 2:

$$
\begin{aligned}
L F G & =R p \quad 7,534 / \mathrm{Nm}^{3} \times 7,500 \mathrm{Nm}^{3} / \text { hari } \\
& =R p \quad 56,505,000 / \text { hari } \\
C N G & =R p \quad 134,144 / \mathrm{Nm}^{3} \times 3,750 \mathrm{Nm}^{3} / \text { hari } \\
& =R p \quad 503,040,000 / \text { hari }
\end{aligned}
$$

Kedua angka tersebut baru dijumlah dan dibagi dengan jumlah output CNG $\left(3,750 \mathrm{~m}^{3}\right)$ untuk mendapatkan HPP pada satuan norm meter kubik. Namun demikian, satuan harga per norm meter kubik ini perlu dikonversi menjadi satuan harga per liter. 1 $\mathrm{Nm}^{3}$ setara dengan 1,000 liter, maka untuk mengetahui HPP per liternya angka tersebut dibagi dengan angka 1,000. Perhitungan dijabarkan sebagai berikut. 
Skenario 1:

$$
\begin{aligned}
& \begin{aligned}
\text { Total HPP } & =H P P \text { LFG }+H P P C N G \\
& =R p 48,345,000+R p 550,398,750 \\
& =R p 598,743,750
\end{aligned} \\
& \begin{aligned}
& H P P\left(\mathrm{Nm}^{3}\right)=\frac{\text { Total } \mathrm{HPP}}{\text { Jumlah Output }}=\frac{R p 598,743,750}{3,750 \mathrm{Nm}^{3}} \\
&=R p 159,665 / \mathrm{Nm}^{3}
\end{aligned} \\
& \text { HPP }(\text { liter })=\frac{H P P\left(\mathrm{Nm}^{3}\right)}{1000 \mathrm{liter} / \mathrm{Nm}^{3}}=\frac{R p 159,665 / \mathrm{Nm}^{3}}{1000 \mathrm{liter} / \mathrm{Nm}^{3}} \\
& =\text { Rp } 160 / \text { liter }
\end{aligned}
$$

Skenario 2:

$$
\begin{aligned}
& \text { Total HPP = HPP LFG +HPPCNG } \\
& =R p 56,505,000+R p 503,040,000 \\
& =R p 559,545,000 \\
& H P P\left(\mathrm{Nm}^{3}\right)=\frac{\text { Total HPP }}{\text { Jumlah Output }}=\frac{R p 559,545,000}{3,750 \mathrm{Nm}^{3}} \\
& =R p 149,212 / \mathrm{Nm}^{3} \\
& H P P(\text { liter })=\frac{H P P\left(\mathrm{Nm}^{3}\right)}{1000 \text { liter } / \mathrm{Nm}^{3}}=\frac{R p 149,212 / \mathrm{Nm}^{3}}{1000 \text { liter } / \mathrm{Nm}^{3}} \\
& =R p 150 / \text { liter }
\end{aligned}
$$

Jadi, harga pokok produk CNG yang dapat dihasilkan oleh TPST Bantar Gebang adalah sebesar Rp 160/liter, sedangkan harga pokok produk CNG yang dapat dihasilkan oleh TPST Bantar Gebang adalah sebesar Rp 150/liter.

\section{KESIMPULAN}

Kapasitas LFG yang digunakan dalam memproduksi CNG adalah sebanyak 5\% dari kapasitas LFG yang sudah ada saat ini, yaitu sebesar 7,500 $\mathrm{Nm}^{3} /$ hari, dan dapat menghasilkan CNG sebanyak 3,570 $\mathrm{Nm}^{3} /$ hari. Harga pokok yang dihasilkan dalam penelitian ini adalah Rp 160 untuk setiap liter produk CNG dengan perhitungan jangka waktu selama 5 tahun dan Rp 150 untuk setiap liter produk CNG dengan perhitungan jangka waktu selama 10 tahun.

Mengingat harga pokok yang cukup rendah, TPST Bantar Gebang sebaiknya segera merealisasikan pengalihan sebagian LFG yang sudah ada untuk dijadikan produk selain listrik, yaitu CNG atau highbtu gas lainnya agar dapat dimanfaatkan menjadi energi alternatif contohnya untuk alat transportasi
Selain $\mathrm{CH}_{4}$ bersih, produk hasil pengolahan yang dilakukan oleh mesin Acrion $\mathrm{CO}_{2}$ WASH adalah $\mathrm{CO}_{2}$ liquid. Produk tersebut juga masih dapat dikembangkan untuk dikomersialisasikan ke masyarakat secara luas, sehingga dapat dipertimbangkan menjadi bisnis baru pada TPST Bantar Gebang.

Melakukan penelitian lanjutan mengenai harga jual yang layak ataupun mengenai analisis kelayakan bisnis dari produk CNG yang telah dilakukan pada penelitian ini

Melakukan penelitian perbandingan keuntungan dan kerugian mengenai produk usulan (CNG) ini dengan produk yang sudah ada yaitu listrik

Melakukan penelitian yang terkait dengan LFGTE (Land Fill Gas To Energy) untuk menghasilkan produk energi lainnya.

\section{DAFTAR PUSTAKA}

1. Acrion Technologies Inc. "Acrion Technologies Inc," Website Acrion. Home page on-line available from http://www.acrion.com; Internet accessed 14 April 2012.

2. Arthur, Richard, Martina, Francisca Baidoo, Edward Antwi. "Biogas as A Potential Energy Source: A Ghanaian Case Study." Elsevier - Renewable Energy 36 (2011): 1510-1516.

3. Batzias, F.A., D.K. Sidiras, E.K. Spyrou. "Evaluating Livestock Manures for Biogas Production: a GIS Based Method." Elsevier - Renewable Energy 30 (2005): 1611-1176.

4. BBC. "Konversi BBM ke BBM, Kebijakan Setengah Hati," Website BBC Indonesia. Home page on-line available from http://www.bbc.co.uk/indonesia/laporan _khusus/2012/01/120130_bbgenergi.sht ml; Internet accessed 29 May 2012.

5. Beck, R.W. "Landfill Gas to Energy Feasibility Report," (2008) City of El Paso Environmental Services Department Online. Home page on-line available from http://www.elpasotexas.gov/sustainabilit y/_documents/Final\%20Report.pdf; Internet accessed 2 May 2012. 
6. Conestoga-Rovers \& Associates. "Landfill Gas Management Facilities Design Guidelines," British Columbia Ministry of Environment Online. Home page on-line available from http://www.env.gov.bc.ca/epd/munwaste/waste-solid/landfills/pdf/Designguidelines-final.pdf;

7. Converti, A, R.P.S. Oliveira, B.R. Torres, A. Lodi, M. Zili. "Biogas Production and Valorization by Means of A Two-Step Biological Process." Elsevier - Bioresource Technology 100 (2009): 5771-5776.

8. Deed, Chris, Jan Gronow, Alan Rosevear, Peter Braithewaite, Richard Smith, Peter Stanley. Guidance on Gas Treatment Technologies for Landfill Gas Engines. Environment Agency Online. Home page on-line available from www.sepa.org.uk/waste/waste_regulatio n/idoc.ashx;

9. Edwards \& Kelcey. Franklin County Sanitary Landfill - Landfill Gas to Liquefied Natural Gas Project. February 2005.

10.ERM. "Feasibility Study of Makassar Landfill Gas Project," Website Pemerintah Makassar. Home page online available from http://makassarkota.go.id/download/mak assar_fs_report_lfg.pdf;

11.Huang and Crookes. "Assessment of Simulated Biogas As A Fuel For The Spark Ignition Engine.” Elsevier - Fuel Vol. 77 No. 15 (1998): 1793-1801.

12.Hullu, J de, J.I.W Maassen, P.A. van Meel, S. Shazad, J.M.P Vaessen. Comparing Different Biogas Upgrading Techniques: Interim Report. Eindhoven University of Technology, April 2008.

13.Kajima, and Yachiyo. Banter Gebang LFG Collection \& Energy Recovery CDM Project. Draft, Kajima Corporation and Yachiyo Engineering, February 2005.

14.Krich, Ken, Don Augstein, JP Batmale, John Benemann, Brad Rutledge, Dara Salour. Biomethane from Dairy Waste: A Sourcebook for the Production and Use of Renewable Natural Gas in California. USDA Rural Development, July 2005.
15.Lenntech. "Water Treatment Solutions," Lenntech Online. Home page on-line available from http://www.lenntech.com/periodic/water /nitrogen/nitrogen-and-water.htm;

16.Ni, J.Q, H. Naveaut, E.J Nynst. "Biogas : Exploitation of a Renewable Energy in Latin America." Pergamon Press Ltd Renewable Energy Vol.3 6/7(1993): 763-779.

17.Pemerintah Indonesia. "Konversi ke BBG Harus Dilakukan," Indonesian Government Online. http://www.indonesia.go.id/in/kementeri an/kementerian/kementerian-negaraperencanaan-pembangunannasionalkepala-bappenas/553energi/10518-konversi-ke-bbg-harusdilakukan.html;

18.Petersson, Anneli and Arthur Wellinger. Biogas Upgrading Technologies Developments and Innovations. IEA Bioenergy: Task 37, October 2007.

19.Raven \& Gregersen. "Biogas Plants in Denmark: Successes and Setbacks." Renewable and Sustainable Energy Reviews xx (2005): 1-18.

20.Roztocki, Narcyz, Jorge F Valezuela, Jose C Porter, Robin M. Monk, Kim LaScola Needy. "A Procedure for Smooth Implementationof Activity Based Costing in Small Companies." Engineering Management Journal (2004).

21.Rubab \& Kandpal. "A Methodology for Financial Evaluation of Biogas Technology in India Using Cost Functions." Biomass and Bioenergy Vol. 10 (1996): 11-23.

22.Sprague, Stephen, Josias Zietman, Tara Ramani. "Prefeasibility Analysis for the Conversion of Landfill Gas to Liquefied Natural Gas to Fuel Refuse Trucks in India," (2009) Global Methane Online. Home page available from http://www.globalmethane.org/Data/218 India_Landfill_Report_-111309.pdf;

23.Terraza, Horacio \& Hans Willumsen. "Guidance Note on Landfill Gas Capture and Utilization." Infrastructure and Environment Sector - Technical Notes No. 108; Inter-American Development Bank, 2009. 